\title{
Effects of Heavy Metals on the Fast Chlorophyll Fluorescence Induction Kinetics of Photosystem II: a Comparative Study
}

\author{
M. Ciscato ${ }^{\mathrm{a}, *}, \mathrm{~J}$. Vangronsveld ${ }^{\mathrm{b}}$ and R. Valcke ${ }^{\mathrm{a}}$ \\ a Limburgs Universitair Centrum, Laboratory of Botany \\ b Laboratory of Environmental Biology, Universitaire Campus Building D, \\ B-3590 Diepenbeek, Belgium. Fax: +32 11 268301. E-mail: mciscato@luc.ac.be \\ * Author for correspondence and reprint requests \\ Z. Naturforsch. 54c, 735 -739 (1999); received November 8, 1998/March 10, 1999 \\ Cadmium, Chlorophyll Fluorescence, Copper, Heavy Metals, Zinc \\ The effects of toxic concentrations of $\mathrm{Cu}, \mathrm{Zn}$ and $\mathrm{Cd}$ on the fast induction kinetics of \\ fluorescence from photosystem(PS)II were investigated in a comparative way. The fast fluo- \\ rescence transient from primary leaves of metal-treated bean plants was studied. During \\ several days after metal application, the time course of the changes induced by the different \\ metals was monitored. The results evidenced not only a different time course of the changes \\ in fluorescence related parameters for the three metals, but also different effects on the \\ fluorescence induction kinetics, which could possibly be linked to different mechanisms of \\ action of the metals.
}

\section{Introduction}

Toxic concentrations of heavy metals in the nutrient medium affect several aspects of the physiology of the plant. Major mechanisms of actions are covalent ion substitution and interaction with $\mathrm{SH}$ groups of proteins, both resulting in the inhibition or inactivation of enzymes (Vangronsveld and Clijsters, 1994; Van Assche and Clijsters, 1990). Noticeably, the photosynthetic apparatus is affected as a consequence of direct or indirect action of the metal ions. In particular $\mathrm{Cu}, \mathrm{Zn}$ and $\mathrm{Cd}$ affect photosynthesis, but the physiology and molecular aspects of their toxic action at this level is not fully understood. Their toxic action in vivo can be the result of interactions at different metabolic levels, resulting in a complex picture. Photosynthesis can be affected in many ways. Metals can cause lipid peroxydation in photosynthetic membranes (Sandmann and Böger, 1980) and affect both synthesis and degradation of photosynthetic pigments,

\footnotetext{
Abbreviations: $\mathrm{F}_{0}=$ initial fluorescence; $\mathrm{F}_{\mathrm{M}}=$ maximal fluorescence: $F_{V}=$ variable fluorescence; $t_{F M}=$ time needed to reach the maximal fluorescence; $\mathrm{A}_{\max }=$ area above the fluorescence induction curve between $t=0$ and $\mathrm{t}=\mathrm{t}_{\mathrm{FM}} ; \mathrm{V}(\mathrm{t})=$ normalized variable fluorescence; $\mathrm{V}_{\mathrm{J}}=\mathrm{V}(2 \mathrm{~ms})$ i.e. at the $\mathrm{J}$ step of the fluorescence induction curve OJIP; $\mathrm{dV} / \mathrm{dt}=$ slope of the $\mathrm{V}(\mathrm{t})$ curve; PAR = photosyntetically active radiation; PSII = photosystem II; RubisCo = ribulose-1,5-bisphosphate carboxylase-oxygenase (EC 4.1.1.39).
}

particularly chlorophyll (Vangronsveld and Clijsters, 1994). A major mechanism of toxic action of metals is the inhibition of the enzyme RubisCo (Clijsters and Van Assche, 1985). This can occur due to ion substitution, as in the case of $\mathrm{Zn}$ (Van Assche and Clijsters, 1986), SH-interaction, as in the case of $\mathrm{Cu}$ and Cd (Stiborova et al. 1988; Stiborova 1988), or as a consequence of enzyme deficiency due to impared protein biosynthesis, as in the case of Cd (Kremer and Markham, 1982).

The inhibition of the RubisCo activity has been proposed as the prevailing toxic effect on photosynthesis after application of excess copper (Lidon and Henriques, 1991). Indirect effect of in vivo copper on the carbon metabolism as a consequence of an altered source-sink relationship has also been proposed (Ciscato et al., 1997). Copper causes also membrane damage at the chloroplast level and changes in thylakoid stacking (Ciscato et al., 1997; Lidon et al., 1993). Direct effects of copper on the two photosystems have been largely investigated (Droppa and Horvath, 1990; Barón et al., 1995), but the applicability of those findings to in vivo situations is not obvious.

Cadmium has been reported to cause inhibition of PSII activity in vivo, due to interaction with the water-splitting enzyme, possibly by substitution of the Mn ions (Baczinsky et al., 1980). Also, metalinduced stomatal closure was early proposed as inhibitory effect of cadmium on photosynthesis 
(Bazzaz et al., 1974). Recent evidence from studies with a novel methodology, the chlorophyll fluorescence image analysis (Ciscato and Valcke, 1998) supports this view. In those experiments, patchy distribution of the chlorophyll fluorescence emission was observed in leaves from Cd-treated bean plants, as probably due to $\mathrm{Cd}$-induced patchy stomatal closure.

The study of the fast, polyphasic chlorophyll fluorescence transient was proven to be a useful tool for the investigation of the response of PSII to environmental stresses (Strasser et al., 1995). From the analysis of the fluorescence induction kinetics it is possible to quantify the behavior of the PSII by means of several parameters. The data can then be interpreted in terms of the capacity of the plant to cope with a stress situation. The response of the plant can be viewed as elastic, when the changes caused by the stress are reversible, or plastic, when the changes are irreversible (Krüger, 1997). However, a plastic response of a plant to a stress situation does not necessarily imply the presence of a damage. More often it can be regarded as stress adaptation.

In an attempt to contribute to the understanding of the effect of metals on the electron transport, the effects of toxic concentrations of $\mathrm{Cu}, \mathrm{Zn}$ and $\mathrm{Cd}$ on the fast induction kinetics of the in vivo fluorescence from PSII were investigated in a comparative way. The different responses to the in vivo treatment with the three metals as related to stress adaptation are also discussed.

\section{Materials and Methods}

Plant material was dwarf bean, Phaseolus vulgaris L. cv. Limburgse vroege. Experiments were performed on plants grown on hydroponics in a growth chamber with a 12 -h photoperiod, constant temperature $\left(22^{\circ} \mathrm{C}\right)$ and humidity $(65 \%)$. Fluorescent tubes (OSRAM L140W/20) and incandescent lamps (Philips 25W) provided light of intensity $150 \mu \mathrm{mol} \cdot \mathrm{m}^{-2} \cdot \mathrm{s}^{-1} \mathrm{PAR}$. Seeds were pre-germinated for 3 days between two layers of rock-wool, soaked with de-mineralized water. Subsequently, the seed coats were removed and 13 seeds per pot were placed on polystyrene boards floating on 31 of Hoagland's solution. The solution was aerated by continuous air flushing. The solution was refreshed on day 4,7 and 10 after the transfer of the seedlings on the nutrient solution. To impose stress, metal ions were supplied on day 7 by addition to the refreshed nutrient solution as $50 \mu \mathrm{m}$ $\mathrm{CuSO}_{4}, 50 \mu \mathrm{m} \mathrm{ZnSO}_{4}$ and $5 \mu \mathrm{m} \mathrm{CdSO}_{4}$. These metal concentrations were sub-lethal, but comparable significant growth reductions could be observed.

Fluorescence induction analysis was carried out in the growth chamber by the Plant Efficiency Analyser (PEA) fluorometer (Hansatech Instruments Ltd., King's Lynn, Norfolk, UK), as described by Strasser et al. (1995). In order to avoid instrument overload, light intensity was set to a saturating level of $540 \mathrm{~W} \mathrm{~m}^{-2}$ red light (peak at $650 \mathrm{~nm}$ ); the $\mathrm{F}_{0}$ as measured by the instrument was used. Before the fluorescence measurement, samples were dark-adapted for 30 minutes in suitable leaf-clips, and the fluorescence transient recorded during $1 \mathrm{~s}$ of illumination over a circular area of $4 \mathrm{~mm}$ diameter. Eight measurements per treatment were taken on randomly chosen primary leaves. Various parameters were obtained: $F_{0}, F_{M}, F_{V}, F_{V} / F_{M}, t_{F M}$ and $\mathrm{A}_{\max }$ were measured or computed by the PEA fluorometer, $\mathrm{V}(\mathrm{t})$ was derived according to Strasser et al. (1995), $\mathrm{V}_{\mathrm{J}}$ being equal to $\mathrm{V}(2 \mathrm{~ms})$, i.e. at the $\mathrm{J}$ step of the fluorescence induction kinetics. $\mathrm{dV} / \mathrm{dt}$ was calculated from the $\mathrm{V}(\mathrm{t})$ curve as $[\mathrm{V}(\mathrm{t}+\mathrm{dt})-\mathrm{V}(\mathrm{t})] / \mathrm{dt}$, where $\mathrm{dt}=10 \mu \mathrm{s}$ in the range $0-2 \mathrm{~ms}$ and $\mathrm{dt}=1 \mathrm{~ms}$ in the range $2-1000 \mathrm{~ms}$. The analysis was performed at intervals of $1,5,24,48$, $72,96,168$ hours after onset of the metal treatment. When the nutrient solution had to be refreshed $(0 \mathrm{~h}$ and $72 \mathrm{~h}$ after the start of metal treatment), measurements were performed just before that.

Due to the asymmetry of the distribution of the values of the fluorescence parameters, the data are presented according to Lazár and Nauš 1998) by means of median (of 8 measurements) and percentiles $\left(25^{\text {th }}\right.$ and $\left.75^{\text {th }}\right)$.

\section{Results and Discussion}

After application of toxic metal concentrations to bean seedlings, different effects of the three metals on the fluorescence induction kinetics were observed. However, not all parameters responded in the same way. Metal application did not have strong effects on the time-course of the well-established parameter $F_{V} / F_{M}$ (data not shown); this in- 
dicates that the photochemical efficiency of PSII was not or only slightly affected by the metal stress supplied in these experiments. Such observation suggests the activity of the photosystem to be quite well preserved, at least in these specific experimental conditions. Nevertheless, analysis of other steps of the induction kinetics evidences a response of the plants to the stress stimulus. The $\mathbf{J}$ step (2 ms after onset of illumination) of the OJIP transient is believed to reflect the start of the $\mathrm{Q}_{\mathrm{A}}$ re-oxidation by $\mathrm{Q}_{\mathrm{B}}$ (Strasser et al., 1995). The time course of the fraction of reduced $\mathrm{Q}_{\mathrm{A}}$ after $2 \mathrm{~ms}$ $\left(\mathrm{V}_{\mathrm{J}}\right.$, Fig. 1) shows that the first effects of the metals

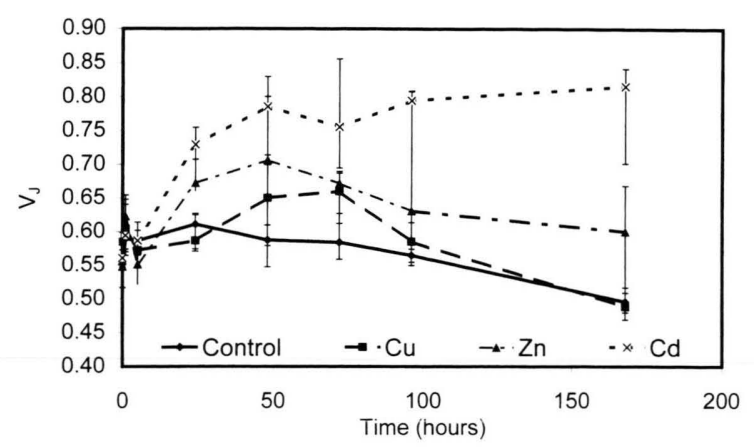

Fig. 1. Time course of the fraction of reduced $\mathrm{Q}_{\mathrm{A}}$ after $2 \mathrm{~ms}\left(\mathrm{~V}_{\mathrm{J}}\right)$ from bean leaves following metal treatment.

occur as early as 24 hours after the onset of the metal treatment. This was not evident from the time course of $\mathrm{F}_{\mathrm{V}} / \mathrm{F}_{\mathrm{M}}$. Furthermore, a different potential of adaptation to the three metals could also be derived from the time course of $\mathrm{V}_{\mathrm{J}}$ : complete recovery for $\mathrm{Cu}$, partial recovery for $\mathrm{Zn}$ and no recovery for $\mathrm{Cd}$. In other terms, while we cannot draw conclusions about the presence of damage only from fluorescence data, it is possible to interpret the above results in terms of plastic and elastic stress-response of PSII (Krüger et al., 1997). In the case of $\mathrm{Cu}$-treatment the response of the bean plants is elastic; i.e. after the application of the stimulus there is a perturbation of the equilibrium, followed by the return to the pre-stimulus state. After $\mathrm{Zn}$ application the response is only partially elastic, although a restoration of control values at later stages cannot be excluded. Cd causes a plastic response; i.e. a new equilibrium is reached but at a different level compared to the control one. Further biochemical investigations will allow to understand whether in the latter case the stressor induced an actual damage or not. Morphological data (not shown), such as reduced growth and chlorosis, indicate that this could be the case.

The different response after $\mathrm{Cu}$ and $\mathrm{Zn}$ compared to $\mathrm{Cd}$ treatment might be attributed to the fact that $\mathrm{Cd}$ is not an essential nutrient. In our experimental conditions, i.e. with sub-lethal doses of metals, the plants seem to be able to adjust to the altered supply of $\mathrm{Cu}$ or $\mathrm{Zn}$, though at different rates. This might be due to a homeostatic capacity of the system. After Cd treatment, on the contrary, the organism undergoes permanent changes although it seems still able to adapt.

The analysis of the kinetics of net $\mathrm{Q}_{\mathrm{A}}$ reduction after one week of metal treatment (Fig. 2) and of the $\mathrm{Q}_{\mathrm{A}}$ reduction rate (Fig. 3) shows that $\mathrm{Cu}$

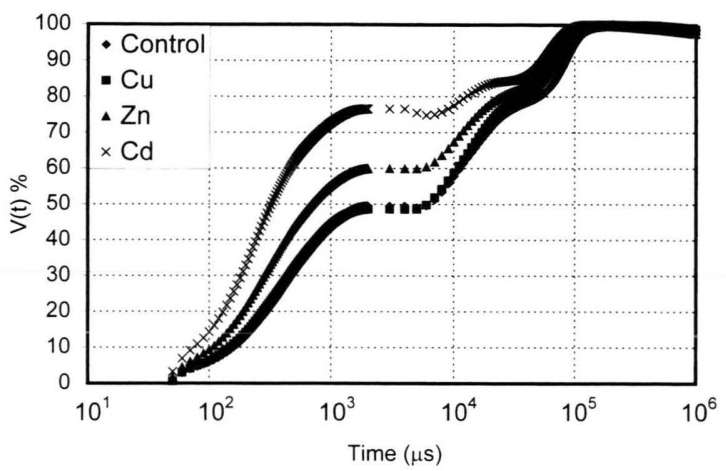

Fig. 2. Kinetics of the net $\mathrm{Q}_{\mathrm{A}}$ reduction from bean leaves after 7 days of metal treatment.

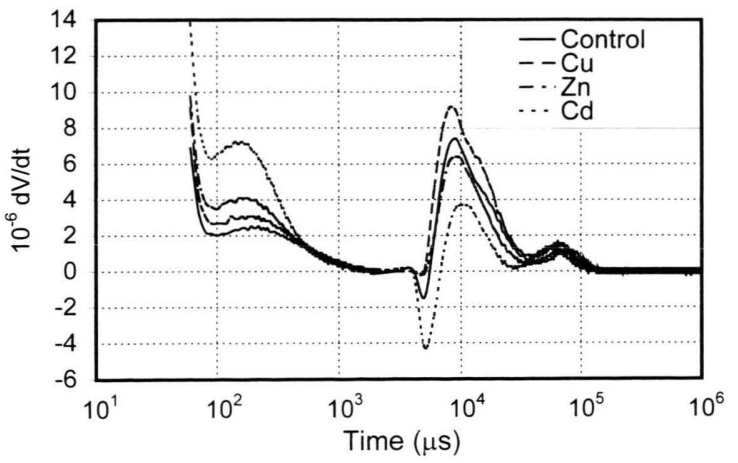

Fig. 3. Rate of net $\mathrm{Q}_{\mathrm{A}}$ reduction from bean leaves after 7 days of metal treatment.

causes changes only after the J-step $(2 \mathrm{~ms})$. The observed pattern might indicate that only the $\mathrm{Q}_{\mathrm{A}}$ re-oxidation is affected. This is different for the two other metals: Cd seems to affect both reduction and re-oxidation of $\mathrm{Q}_{\mathrm{A}}$ (effects were ob- 
served both before and after the J-step) and $\mathrm{Zn}$ only its reduction (effects were observed only before the J-step). However, $\mathrm{Cu}$ and $\mathrm{Cd}$ seem to affect the $\mathrm{Q}_{\mathrm{A}}$ re-oxidation in a different way. Compared to the control $\mathrm{Cu}$ induces a faster net reduction of the $\mathrm{Q}_{\mathrm{A}}$ pool after the J-step while Cd slows down the reaction. The growth kinetics of the area above the fluorescence induction curve (Fig. 4) confirms this interpretation: a slower area growth in $\mathrm{Cd}$ - and $\mathrm{Cu}$-treated plants was found compared to the control. This suggests a back-pressure from the electron transport, which could cause problems to $\mathrm{Q}_{\mathrm{A}}$ re-oxidation. Such back-pressure might be caused by an inhibition of the Calvin cycle. Down-regulation of the electron transport as consequence of the inhibition of enzymes of the Calvin cycle was previously proposed for Cd (Krupa et al., 1993; Siedlecka and Krupa, 1996). The present results seem to support such explanation. However, a direct effect of $\mathrm{Cd}$ on the $\mathrm{Q}_{\mathrm{A}}-\mathrm{Q}_{\mathrm{B}}$ electron transfer (as indicated by the increase in $\mathrm{V}_{\mathrm{J}}$ ) cannot be excluded due to the possible interaction of $\mathrm{Cd}$ with the non-heme $\mathrm{Fe}$ involved in this step of the electron transport. $\mathrm{Cu}$ inhibition of the Calvin cycle has also been proposed (Lidon and Henriques, 1991). In a previous study on $\mathrm{Cu}$-treated wheat plants (Ciscato et al., 1997) we explained similar effects as caused by a reduced request of photosynthesis products due to altered source-sink relationship.

Zn-treated plants did not show remarkable changes in the kinetics of area growth (Fig. 4), confirming that this element probably does not affect the $\mathrm{Q}_{\mathrm{A}}$ re-oxidation.

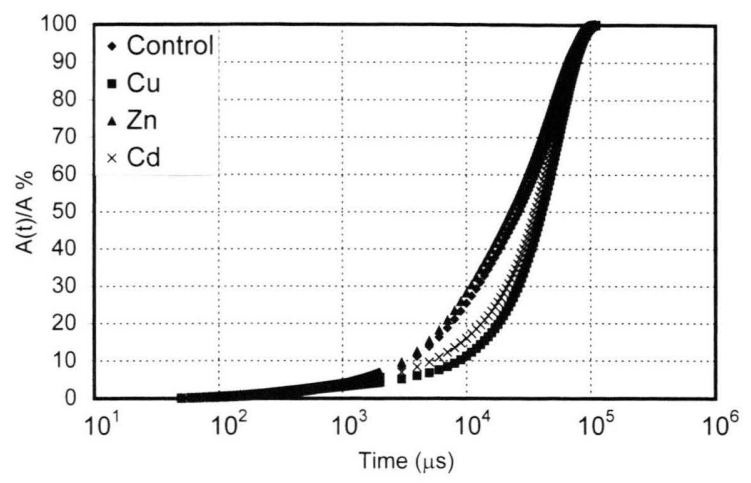

Fig. 4. Growth kinetics of the area above the fluorescence induction curve from bean leaves after 7 days of metal treatment.

The results of this work strongly suggest that, at least concerning the photosynthetic process, the search for a common "heavy-metal-syndrome" could be misleading. The heterogeneity of the observed in vivo effects of the different metals studied indicates that the responses at the level of PSII must be considered to be rather metal-specific than being part of a common response to heavy metal stress.

\section{Acknowledgements}

Most of the data presented in this paper are results obtained from a study performed for the OVAM (Openbare Afvalstoffenmaatschappij voor het Vlaamse Gewest), Belgium. 
Barón M., Arellano J. B. and López Gorgé J. (1995), Copper and photosystem II: a controversial relationship. Physiol. Plant. 94, 174-180.

Baczinsky T., Wajda L., Krol M., Wolinska D., Krupa Z. and Tukendorf A. (1980), Photosynthetic activities of cadmium-treated tomato plants. Physiol. Plant. 48, 365-370.

Bazzaz F. A., Carlson R. W. and Rolfe G. L. (1974), The effect of heavy metals on plants: Part I. Inhibition of gas exchange in sunflower by $\mathrm{Pb}, \mathrm{Cd}, \mathrm{Ni}$ and $\mathrm{Tl}$. Environ. Pollut. 7, 241-246.

Ciscato M. and Valcke R. (1998), Chlorophyll fluorescence imaging of heavy metal treated plants. In: Photosynthesis: Mechanisms and Effects (G. Garab ed.). Vol. IV. Kluwer Academic Publishers 2661-2663.

Ciscato M., Valcke R., Van Loven K., Clijsters H. and Navari-Izzo F. (1997), Effects of in vivo copper treatment on the photosynthetic apparatus of two Triticum durum cultivars with different stress sensitivity. Physiol. Plant. 100, 901-908.

Clijsters H. and Van Assche F. (1985), Inhibition of photosynthesis by heavy metals. Photosynth. Res. 7, 32-40.

Droppa M. and Horváth G. (1990), The role of copper in photosynthesis. CRC Crit. Rev. Plant Sci. 9, 111-123.

Kremer B. P. and Markham J. W. (1982), Primary metabolic effect of cadmium in brown alga, Laminaria saccharina. Z. Pflanzenphysiol. 108, 125-130.

Krüger G. H. J., Tsimilli-Michael M. and Strasser R. (1997), Light stress provokes plastic and elastic modifications in structure and function of photosystem II in camellia leaves. Physiol. Plant. 101, 265-277.

Lazár and Nauš (1998) Statistical properties of chlorophyll fluorescence induction parameters. Photosynthetica 35, $121-127$.

Lidon F. C. and Henriques F. S. (1991), Limiting step on photosynthesis of rice plants treated with varying copper levels. J. Plant Physiol. 138, 115-118.
Lidon F. C., Ramalho J. C. and Henriques F. S. (1993), Copper inhibition in rice photosynthesis. J. Plant Physiol. 142, 12-17.

Sandmann G. and Böger P. (1980), Copper-mediated lipid peroxidation processes in photosynthetic membranes. Plant Physiol. 66, 797-800.

Siedlecka A. and Krupa Z. (1996), Interaction between cadmium and iron and its effect on photosynthetic capacity of primary leaves of Phaseolus vulgaris. Plant Physiol. Biochem. 34, 833-842.

Stiborova M. (1988), $\mathrm{Cd}^{2+}$ ions affect the quaternary structure of ribulose-1,5-bisphosphate carboxylase from barley leaves. Biochem. Physiol. Pflanzen 183, $371-378$.

Stiborova M., Ditrichova M. and Benzinova A. (1988), Mechanism of action of $\mathrm{Cu}^{2+}, \mathrm{Co}^{2+}$ and $\mathrm{Zn}^{2+}$ on ribulose-1,5-bisphosphate carboxylase from barley (Hordeum vulgare L.). Photosynthetica 22, 161-167.

Strasser R. J., Srivastava A. and Govindjee (1995), Polyphasic chlorophyll $a$ fluorescence transient in plants and cyanobacteria. Photochem. Photobiol. 61, 32-42.

Van Assche F. and Clijsters H. (1986), Inhibition of photosynthesis in Phaseolus vulgaris by treatment with toxic concentrations of zinc: Effect on ribulose-1,5bisphosphate carboxylase / oxygenase. J. Plant Physiol. 125, 355-360.

Van Assche F. and Clijsters H. (1990), Effects of metals on enzyme activity in plants. Plant, Cell Environ. 13, $195-206$.

Vangronsveld J. and Clijsters H. (1994) Toxic effects of metals. In: Plants and the Chemical elements (M. E. Farago ed.). VCH Weinheim, ISBN 3-527-28269-6, pp. $149-175$. 